\title{
Thermally Induced Phase Changes, Lateral Heterogeneity of the Mantle, Continental Roots, and Deep Slab Anomalies
}

\author{
DON L. ANDERSON
}

\author{
Seismological Laboratory, California Institute of Technology, Pasadena, California
}

\begin{abstract}
Pressure-induced solid-solid phase changes are responsible for most of the increase of density and seismic velocity with depth in the upper mantle. Lateral variations in temperature cause a similar effect; abrupt changes of density and seismic velocity due to phase changes are superposed on smaller changes associated with thermal expansion. Temperature-induced isobaric phase changes are as important in explaining various recent geophysical data as are the more familar pressure-induced phase changes. In cold slabs the equilibrium mineral assemblage contains high-density, high-velocity phases which are not stable in hotter mantle. In particular, the ilmenite form of $\mathrm{MgSiO}_{3}$ and the $\gamma$-spinel form of $\mathrm{Mg}_{2} \mathrm{SiO}_{4}$ have broad stability fields in cold mantle which increase the density and velocity of deep slabs to values in excess of those which have been used in geoid and seismic travel time modeling. Recent arguments for slab penetration into the lower mantle and whole mantle convection are based on thermal models of the slab which ignore the large density and seismic velocity anomalies associated with temperature-induced phase changes. When these effects are taken into account, the geoid and seismic anomalies associated with subducted slabs are consistent with slab confinement to the upper mantle and layered models of mantle convection. The seismicity cutoff and evidence for slab thickening at $670 \mathrm{~km}$ also favor this style of convection. Mantle seismic velocities between 200 and $400 \mathrm{~km}$ depth in tectonic and young oceanic regions are lower than in shield regions, and this is due to the presence of a melt phase and lowervelocity, high-temperature phase assemblages. Deep, $>200 \mathrm{~km}$, long-lived continental roots, differing in chemistry from "normal" mantle, are not required when isobaric phase changes are taken into account. High-velocity subshield mantle is closer to normal subsolidus mantle than is suboceanic mantle which is affected by the presence of high-temperature phase assemblages. The whole mantle convection, thick continental root, and deep slab penetration hypotheses are not supported by seismic and geoid data when isobaric phase changes are included in the analysis. Phase changes are more effective in changing density and seismic velocity than are lateral variations in temperature and composition. The lack of correlation of the geoid with ridges, shields, heat flow, and upper mantle velocity variations suggests a low geoid sensitivity to the upper mantle, consistent with layered convection.
\end{abstract}

\section{INTRODUCTION}

As the ability to map the three-dimensional structure of the Earth improves, it becomes important to understand the factors which influence the lateral heterogeneity in density and seismic velocities. Much of the radial structure of the Earth is due to changes in mineralogy resulting from pressure-induced equilibrium phase changes or changes in composition. The phase fields depend on temperature as well as pressure so that, for example, a given mineral assemblage will occur at a different depth in colder parts of the mantle. The elevation, in radius, of the olivine-spinel phase boundary in cold slabs is probably the best known example of this effect. The other important minerals of the mantle, orthopyroxene, clinopyroxene, and garnet, also undergo temperature dependent phase changes to denser phases with higher elastic moduli. These phases include majority, ilmenite, spinel plus stishovite, and perovskite. The pronounced low-velocity zone under oceans and tectonic regions and its suppression under shields are another example of phase differences (partial melting) associated with lateral temperature gradients.

Temperature provides more than just a perturbation to the depths of phase boundaries. Variations in temperature, at constant pressure, also cause changes in the stable mineral assemblages, and these isobaric phase changes result in larger changes in the physical properties than are caused by the

Copyright 1987 by the American Geophysical Union.

Paper number $7 \mathrm{~B} 1028$.

0148-0227/87/007B-1028\$05.00 effect of temperature within an assemblage without phase changes. In general, the sequence of phase changes that occurs with increasing pressure also occurs with decreasing temperature. There are also some mineral assemblages that do not exist under normal conditions of pressure and temperature but occur only under the extremes of temperature found in cold slabs or near the solidus in hot upwellings. Generally, the cold assemblages are characterized by higher density and higher elastic moduli.

The magnitude of the horizontal temperature gradients in the mantle is unknown, but slab modeling gives about $800^{\circ} \mathrm{C}$ over about $50 \mathrm{~km}$ [e.g., Toksöz et al., 1971; Griggs, 1972]. Kaula [1983] gives a more global estimate of upper mantle temperature variations based on plate motions and heat flow data. Long-wavelength temperature variations at $280 \mathrm{~km}$ are at least $\pm 180^{\circ}$. In an internally heated material the upwellings are much broader than slabs or downwellings. Tomographic results give extensive low-velocity regions associated with ridges and tectonic regions, consistent with broad hightemperature regions [Nataf et al., 1986]. The cores of convection cells have relatively low thermal gradients. We therefore expect the role of isobaric phase changes to be most important and most concentrated in regions of subducting slabs. The temperature drop across a downwelling is roughly equivalent to a pressure increase of $50 \mathrm{kbar}$, using typical Clapeyron slopes of upper mantle phase transitions. The effect of phase changes on mantle convection has been treated by Kaula [1980].

The lateral variation of seismic velocity in the mantle above $400 \mathrm{~km}$ has been known for some time. Shield areas have much higher velocities $(\sim 10 \%)$ to $150-200 \mathrm{~km}$ [Brune and 
TABLE 1. Phase Changes, Their Approximate Depth Extent in "Normal" Mantle, and the Approximate Density Contrasts

\begin{tabular}{llc}
\hline Depth, km & \multicolumn{1}{c}{ Phase Change } & Density Contrast, $\%$ \\
\hline $50-60$ & basalt $\rightarrow$ eclogite & 15 \\
$50-60$ & spinel peridotite $\rightarrow$ garnet peridotite & 3 \\
$50-200$ & partial melting & 10 \\
$400-420$ & olivine $\rightarrow \beta$-spinel & 7 \\
$300-400$ & orthopyroxene $\rightarrow$ majorite & 10 \\
$500-580$ & $\rightarrow \beta+$ st & 4.5 \\
& $\rightarrow \gamma+$ st & 1.6 \\
$500-580$ & $\beta$-spinel $\rightarrow \gamma$-spinel & 3 \\
$400-500$ & clinopyroxene $\rightarrow$ garnet & 10 \\
500 & garnet-majorite s.s. $\rightarrow$ ilmenite s.s. & 5 \\
700 & ilmenite $\rightarrow$ perovskite & 5 \\
\hline
\end{tabular}

Here st is stishovite and s.s. is solid solution.

Dorman, 1963; Anderson, 1967a; Toksöz et al., 1967] and slightly higher velocities $(\sim 3-5 \%)$ to about $400 \mathrm{~km}$ [Anderson, 1967a; Grand and Helmberger, 1984; Nataf et al., 1984, 1986; Grand, 1986] than tectonic or oceanic regions. This has been explained in terms of partial melting under the slower, hotter regions [Anderson and Sammis, 1969, 1970; Anderson and Spetzler, 1970] and normal effects of temperature and pressure along the $1400^{\circ} \mathrm{C}$ adiabat under shields [Anderson and Bass, 1984], rather than a deep continental root. The large lateral velocity contrast is a result of the magnification of the effect of temperature by partial melting and other phase changes. Between about 300 and $400 \mathrm{~km}$ the depression of the olivine-spinel and orthopyroxene-majorite phase boundaries under warmer regions is also involved. The high velocities in the upper $150 \mathrm{~km}$ of the shields are due to low temperatures and a refractory, but buoyant, olivine-rich shield lithosphere as well as the absence of a partial melt. Jordan [1975] and Sipkin and Jordan $[1975,1976]$ proposed that the refractory nature of shields extends to at least $400 \mathrm{~km}$ and possibly more than $600 \mathrm{~km}$. Instead of accepting the evidence that young oceanic-tectonic mantle is abnormally slow, because of partial melting, they proposed that shields were abnormally fast, because of compositional differences, and had conductive roots in excess of $400 \mathrm{~km}$ depth. The absence of geoid anomalies associated with shields [Turcotte and McAdoo, 1979] is also inconsistent with a thick, $>200 \mathrm{~km}$, chemically distinct shield root unless there is a fortuitous cancellation of temperature and chemical effects. Anderson and Bass [1984] showed that the mantle under shields to a depth of $\sim 150 \mathrm{~km}$ required both low temperatures and a seismically fast mineralogy, both ef fects operating in the same direction. Lateral variations in density and seismic velocity due to isobaric phase changes at depths greater than $400 \mathrm{~km}$ have not received much attention.

\section{LATERAL VARIATIONS OF TEMPERATURE}

In the recent geophysics literature it is often assumed that lateral variations in density and seismic velocity are due to temperature alone. By contrast, it is well known that radial variations are controlled not only by temperature and pressure but also by pressure-induced phase changes. Phase changes such as partial melting, basalt-eclogite, olivine-spinelpostspinel, and pyroxene-majorite-perovskite dominate the radial variations in density and seismic velocity. It would be futile to attempt to explain the radial variations in the upper mantle, particularly across the 400 - and $650-\mathrm{km}$ discontinuities, in terms of temperature and pressure and a constant mineralogy. All of the above phase changes, plus others, also occur as the temperature is changed at constant pressurc or depth. Yet it is common practice to ignore these temperatureinduced phase changes in attempting to explain geophysical anomalies associated with the geoid and slabs and the oceancontinent contrast. This has led to models requiring deep slab penetration since temperature alone is not sufficient to explain the magnitude of the anomalies if slabs are confined to the upper mantle. Likewise, the integrated travel time contrast between shields and' oceans [e.g., Sipkin and Jordan, 1975] implies a thick continental root unless lateral phase changes, such as partial melting, are allowed for. In any case, the large lateral variations in velocity above $300 \mathrm{~km}$ and, particularly, above $200 \mathrm{~km}$ make it difficult to resolve variations below 400 $\mathrm{km}$, and those that do exist are small and uncorrelated with shields [Nataf et al., 1986; Anderson, 1987b]. Lateral density and velocity variations associated with phase changes are not confined to narrow depth intervals nor are they all associated with simple elevation of phase boundaries in cold mantle. The combination of cold temperature and high pressure can stabilize assemblages which are not present in warmer mantle and can broaden, in depth, the stability fields of high-density minerals.

There are large geoid and seismic velocity anomalies associated with subducting slabs [Davies and McKenzie, 1969; Hager, 1984; Creager and Jordan, 1984]. Ordinary temperature effects are so small that slab penetration deep into the lower mantle has been invoked in order to explain the size of the anomalies. This, in turn, has been used by some to support models of whole mantle convection and to reject chemically stratified models with slabs confined to the upper mantle. Hager [1984] pointed out that chemical stratification would require a larger density contrast to be associated with slabs than expected from temperature and the olivine-spinel phase transition alone.

Because of lateral temperature gradients we have to be concerned with lateral, or isobaric, phase changes as well as radial phase changes. Some of these phase changes, their approximate depth extent in "normal" mantle, and the approximate density contrast are given in Table 1. For a multicomponent mantle the percentages given in Table 1 must be multiplied by the fraction of mantle involved. Ringwood [1982] gives a convenient summary of the densities of mantle phases. The density contrasts depend slightly on temperature and pressure but less so than the absolute densities.

Most of these reactions have positive Clapeyron slopes and are therefore elevated in cold slabs and depressed in hot upwellings. The density contrasts are much larger than those associated with thermal expansion and, in any case, add to the thermal expansion effect. This is important in geoid modeling. The associated velocity contrasts are important in modeling lateral changes in seismic velocity and slab anomalies. For a typical coefficient of thermal expansion of $3 \times 10^{5}{ }^{\circ} \mathrm{C}^{-1}$ it requires a $\Delta T$ of $10^{3}{ }^{\circ} \mathrm{C}$ to change the density by $3 \%$. Since the thermal coefficients of density and elastic moduli decrease with compression [e.g., Anderson, 1987a], it is even more difficult to obtain large lateral variations at depth with temperature alone.

\section{Mineralogy of the Mantle}

The most abundant minerals of the upper mantle are most likely olivine, orthopyroxene, clinopyroxene, and garnet, but the relative proportions are unknown. Both periodotite, mainly olivine and orthopyroxene, and eclogite, mainly clin- 


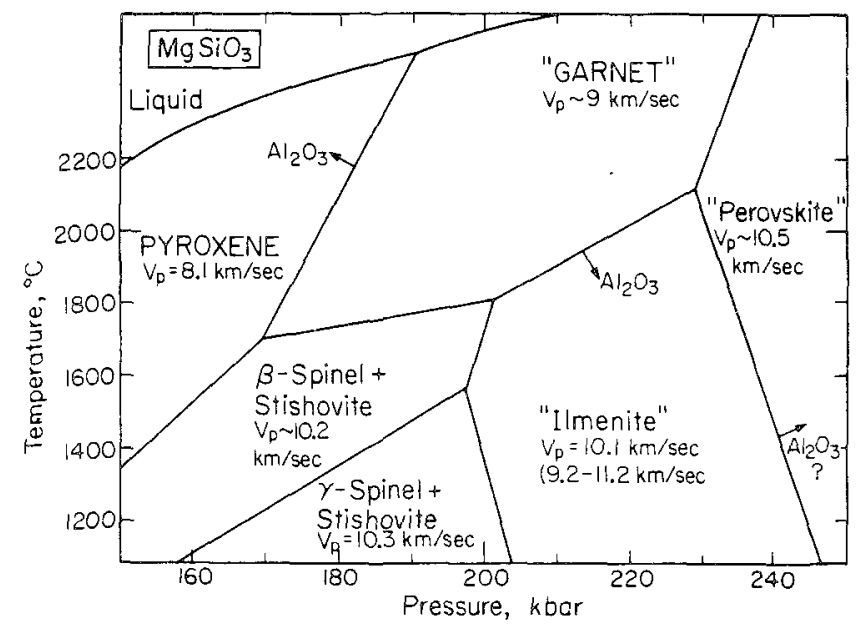

Fig. 1. Provisional phase relations in $\mathrm{MgSiO}_{3}$ (modified from Kato and Kumazawa [1985], Sawamoto [1986], and Akaogi et al. [1986]). The arrows show the direction that the phase boundaries are expected to move when $\mathrm{Al}_{2} \mathrm{O}_{3}$, or garnet, is added. The approximate compressional velocities are shown for each phase.

opyroxene and garnet, satisfy the seismic velocities in subsolidus regions of the upper $400 \mathrm{~km}$ [Anderson and Bass, 1984]. Xenoliths contained in basalts and peridotites exposed in mountain belts, fracture zones, and ophiolites are predominantly olivine and orthopyroxene. Cosmochemically, pyroxenes are expected to be the most abundant minerals since the atomic ratio of $\mathrm{Mg}$ to $\mathrm{Si}$ is closer to 1 than to 2 in solar and chondritic abundances. Olivine $(\mathrm{Mg} / \mathrm{Si} \sim 2)$ is less dense than gamet peridotite and eclogite, and it will tend to concentrate in the shallow mantle.

The most abundant material, by far, that emerges from the mantle is basalt. This crystallizes to clinopyroxene and garnet, the eclogite assemblage, at moderate pressure $\sim 20 \mathrm{kbar}$. Basalis may have experienced some olivine fractionation prior to eruption from a picritic parent. Olivine and orthopyroxene are the most refractory upper mantle phases so these will tend to be left behind in the shallow mantle when picrite or basalt is removed. Based on cosmochemical considerations, the basaltic fraction of the mantle is 10-15\% [Anderson, 1982c], but it is not yet clear whether this is distributed uniformly or concentrated into the upper mantle or transition region. It probably varies laterally and radially. A mantle with chondritic $\mathrm{Mg} / \mathrm{Si}$ ratios would be predominately orthopyroxene with olivine being the second most abundant component. Differentiation of the Earth may concentrate basalt and olivine into the upper mantle and orthopyroxene into the lower mantle [Anderson, 1979a, b, c, 1981a,b, 1982a, b, c; Anderson and Bass, 1986; Ohtani, 1983, 1985]. Thermal convection may act to partially rehomogenize the mantle, but the presence of isotopic heterogeneity in mantle magmas is inconsistent with complete homogenization. In any event, the most abundant minerals in the upper mantle are olivine, orthopyroxene, clinopyroxene, and garnet. It is the properties of these minerals and their high-temperature, high-pressure phases that control the radial and lateral variations in density and seismic velocity.

\section{$\mathrm{MGSiO}_{3}$ SYSTEM}

Phase relations in olivine are fairly well understood and will not be treated in detail here. Orthopyroxene, the second most abundant mineral in peridotite, is a sold solution of $\mathrm{MgSiO}_{3}-\mathrm{FeSiO}_{3}$ with limited solubility of $\mathrm{CaO}$ and $\mathrm{Al}_{2} \mathrm{O}_{3}$. Recent high-pressure, high-temperature experiments have helped elucidate the phase relations in $\mathrm{MgSiO}_{3}$, the main component of the orthopyroxene system. A preliminary synthesis of available results is given in Figure 1 . Note that the high-temperature sequence of transitions is different from the low-temperature sequence. The resulting densities and seismic velocities are also quite different. The garnet form of $\mathrm{MgSiO}_{3}$, majorite [Ringwood and Major, 1971], is dominant at high temperature. Majorite is similar to pyrope garnet with ${ }^{\mathrm{VI}} \mathrm{Mg}^{\mathrm{VI}} \mathrm{Si}$ replacing ${ }^{\mathrm{VI}} \mathrm{Al}_{2}$ yielding

$$
{ }^{\mathrm{V}}{ }^{\mathrm{III}} \mathrm{Mg}_{3}{ }^{\mathrm{VI}}[\mathrm{MgSi}]^{\mathrm{IV}} \mathrm{Si}_{3} \mathrm{O}_{12}
$$

where the roman numerals refer to coordination. Since ${ }^{\mathrm{V}}[\mathrm{MgSi}] \mathrm{O}_{3}$ (periclase plus stishovite) has elastic properties similar to ${ }^{\mathrm{V}} \mathrm{Al}_{2} \mathrm{O}_{3}$, we expect majorite to have elastic properties similar to pyrope.

"Ilmenite," vi $\mathrm{Mg}^{\mathrm{v}} \mathrm{SiO}_{3}$, a high-pressure, low-temperature form of enstatite, has considerable higher elastic moduli [Weidner, 1985] since all of the $\mathrm{Si}$ is in six-fold coordination as in stishovite. Ilmenite is extremely anisotropic. The lowtemperature minerals (spinel + stishovite, ilmenite) are $10-20 \%$ higher in velocity than the high-temperature minerals (pyroxene, majorite).

The temperatures in the mantle are unknown, but for temperature contrasts of $\sim 800^{\circ} \mathrm{C}$ the mineral assemblages are different for almost all pressures between 17 and $24 \mathrm{GPa}$, virtually the entire transition region. The low-temperature assemblages, $\beta+$ stishovite(st), $\gamma+$ st and ilmenite, are of the order of $10 \%$ faster than "garnet" or majorite. The locations of the phase boundaries depend on $\mathrm{Al}_{2} \mathrm{O}_{3}$ content, and the expected migration direction is given by the arrows. Note that the "garnet" form of pyroxene (majorite) is stabilized by hightemperature and high $\mathrm{Al}_{2} \mathrm{O}_{3}$ content. Also, ordinary pyroxene is stable to relatively high pressures in hot mantle. This is partially responsible for the low velocities in the upper mantle under oceanic and tectonic regions.

\section{CMAS SYSTEM}

Kuskov and Galimzyanov [1986] have summarized the phase relations in the system $\mathrm{CaO}-\mathrm{MgO}-\mathrm{Al}_{2} \mathrm{O}_{3}-\mathrm{SiO}_{2}$ (CMAS). The phases of $\mathrm{Mg}_{2} \mathrm{SiO}_{4}$ are olivine $(\alpha), \beta$-spinel $(\beta)$, $\gamma$-spinel $(\gamma)$, and perovskite $+\mathrm{MgO}$. The major phases of $\mathrm{MgSiO}_{3}$ are enstatite, majorite, ilmenite, and perovskite ( $\mathrm{Mg}$ pv). At low temperatures and when no, or little, $\mathrm{Al}_{2} \mathrm{O}_{3}$ is present, there are also extensive fields of $\beta+s t$ and $\gamma+s t$. High temperatures and the presence of $\mathrm{Al}_{2} \mathrm{O}_{3}$ stabilize the majorite structure, and a broad majorite-garnet solid solution (s.s.) field occurs between enstatite, ilmenite, and perovskite. Diopside and jadeite, components of clinopyroxene, are stable to higher pressures than enstatite. Diopside collapses to a dense Ca-rich phase, probably perovskite (Ca-pv) at pressures less than required to transform enstatite to perovskite [Ringwood, 1975, 1982]. Garnet itself is stable throughout most of the upper mantle, although it dissolves pyroxene with increasing pressure. At very high pressure, garnet transforms to an $\mathrm{Al}_{2} \mathrm{O}_{3}$-rich perovskite (Al-pv) [Liu, 1974]. The lower mantle below about $750 \mathrm{~km}$ probably consists of three perovskites plus magnesiowïstite $(3 \mathrm{pv}+\mathrm{mw})$.

The $\alpha-\beta$ transition is elevated by $30 \mathrm{kbar}$ and the $\beta-\gamma$ transition is elevated by $40 \mathrm{kbar}$ by a decrease in temperature of $800^{\circ} \mathrm{C}$. In the case of enstatite, not only is the upper stability 
limit decreased at low temperature, but the low-temperature phase assemblages are different. The dense and fast phase $\gamma$ spinel has a much broader stability field in cold mantle.

High-pressure petrological experiments and thermochemical calculations have provided information about the approximate stability fields of high-pressure minerals at various temperatures. Uncertainties in pressure, solid solution, and kinetic effects and the lack of systematic and reversed data make it impossible to draw accurate equilibrium boundaries between the various phase fields. The general locations and shapes of the phase boundaries, however, are now well enough known so that the effects of isobaric phase changes, over the temperature range appropriate for the mantle, can be discussed at about the same level as isothermal phase changes were discussed some 20 years ago in relation to the radial structure of the mantle [e.g., Anderson, 1967a, b, 1970]. At that time it was clear that the rapid increases in seismic velocity near 400 and $650 \mathrm{~km}$ could be explained by solid-solid phase changes in the olivine and pyroxene components of the mantle, even though the available direct high-pressure experimental petrological evidence was extremely sparse. We are in about the same position today with respect to the effect of temperature on the stability fields of high-pressure minerals: a few scattered experiments supplemented by knowledge of the thermochemical properties of many of the pertinent phases.

We have taken all available synthesis data on the temperature and pressure at which various phases have been observed or recovered (see references in the captions to Figures 1 and 4) and have drawn preliminary boundaries between the various phase fields, taking into account, when possible, theoretical slopes from estimates of volume and entropy changes. We call this a "provisional facies map" rather than a "phase equilibria diagram" to indicate its schematic and uncertain nature. The majority of the data is for simple systems and is unreversed. We have therefore probably erred in the direction of simplicity and may have overestimated pressures. In most of our discussion we are concerned with the changes in mineralogy and density over the temperature range thought to exist in the mantle rather than the exact temperature and distance range over which the transformation occurs. The seismic data also have limited resolution, and uncertainties of several hundred degrees and tens of kilobars in the phase diagrams have little effect on our conclusions which have more dependence on the existence of isobaric phase changes and the relative densities of the various phases. Isobaric phase changes would be unimportant only if $\Delta S, \Delta V$, or $\Delta S / \Delta V$ were very small, and these conditions are not true for the phase changes discussed here.

Because of the incomplete and reconnaissance nature of the high-pressure, high-temperature petrological experiments the details of the density profiles that we calculate are also provisional and subject to change. However, the total density changes associated with the solid-solid transformations are well known, and the experimental petrological data are used only to estimate where these density changes occur.

At normal mantle temperatures the peridotite mineral assemblage, olivine + pyroxenes + garnet, stable in the shallow mantle, transforms to $\beta$ - or $\gamma$-spinel + "garnet" ss (majorite+ garnet) \pm clinopyroxene \pm stishovite at the top of the transition region with a substantial increase in density and seismic velocity. At lower temperatures this assemblage is replaced by ilmenite, $\gamma$-spinel, and magnesiowustite $\pm \mathrm{Ca}$-rich perovskite. Near $700 \mathrm{~km}$ the normal mineral assemblage is two per- ovskites plus garnet, while the cold assemblage is three perovskites or Ca-perovskite plus garnet plus ilmenite \pm oxides. Below $800 \mathrm{~km}$ the assemblages should be independent of temperature over the temperature range expected in the lower mantle. Temperature-induced variations in density and velocity should therefore be relatively small in the lower mantle. The negative Clapeyron slope for the ilmenite-perovskite transition means that cold slabs subducting to the base of the transition region or pushed into the top of the lower mantle will be less dense than normal lower mantle. The high velocity of ilmenite, however, means that the velocity in the vicinity of deep focus earthquakes is much faster than adjacent mantle.

The mineralogy of a peridotite mantle and the approximate zero-pressure density as a function of temperature, at two pressures, is shown in Figure 2. Temperature is plotted increasing upward to emphasize the fact that decreasing temperature has effects similar to increasing pressure. The curve labeled $\alpha \Delta T$ is the approximate effect of thermal expansion alone on density, taking into account the increase of $\alpha$ with temperature and its change with mineralogy [e.g., Jeanloz and Knittle, 1986]. The bar labeled $800^{\circ} \mathrm{C}$ shows the expected change in temperature across a subducted slab and is approximately half the maximum expected lateral temperature changes in the mantle. Note that a temperature change of $800^{\circ} \mathrm{C}$ placed anywhere in the field of temperatures expected in the mantle will cross one, two, or even three phase boundaries, each of which contributes a $\Delta \rho$ in addition to the $-\Delta \rho / \rho=\alpha \Delta T$ from thermal expansion. Changes in elastic properties are also associated with these phase changes.

The density change associated with a temperature change of $800 \mathrm{~K}$ ranges from 7 to $17 \%$ in the temperature interval 1000 to $2300 \mathrm{~K}$ at pressures of 180 and $200 \mathrm{kbar}$. This includes themal expansion and isobaric phase changes. Thermal expansion alone gives $2-3 \%$. The density anomaly associated

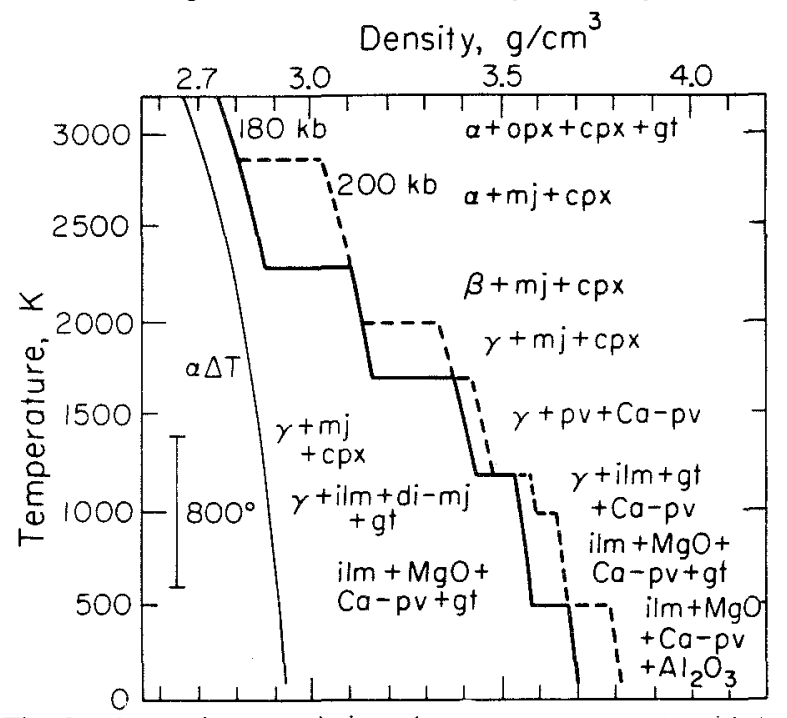

Fig. 2. Approximate variation of zero-pressure density with temperature taking into account thermal expansion (curve to left) and phase changes at two pressures. The effect of pressure on density is not included; $x \Delta T$ is not linear since $\alpha$ increases with $T$ and generally decreases from low-density phases to high-density phases. The inclusion of density jumps associated with phase changes increases the average effect of temperature by a factor of $3-4$. At phase boundaries the effect is much larger. The phases stable over each temperature interval are also shown. The abbreviations are $\alpha$ (olivine), $\beta$ ( $\beta$-spinel), ; ( $;$-spinel), opx (orthopyroxene), cpx (clinopyroxene), gt (garnet), mj ( $\mathrm{MgSiO}_{3}$-majorite), pv ( $\mathrm{MgSiO}_{3}$-perovskite), $\mathrm{Ca}$-pv $\left(\mathrm{CaSiO}_{3}\right.$ perovskite), ilm ( $\mathrm{MgSiO}_{3}$-ilmenite), mw (magnesiowüstite), s.s. (solid solution). 


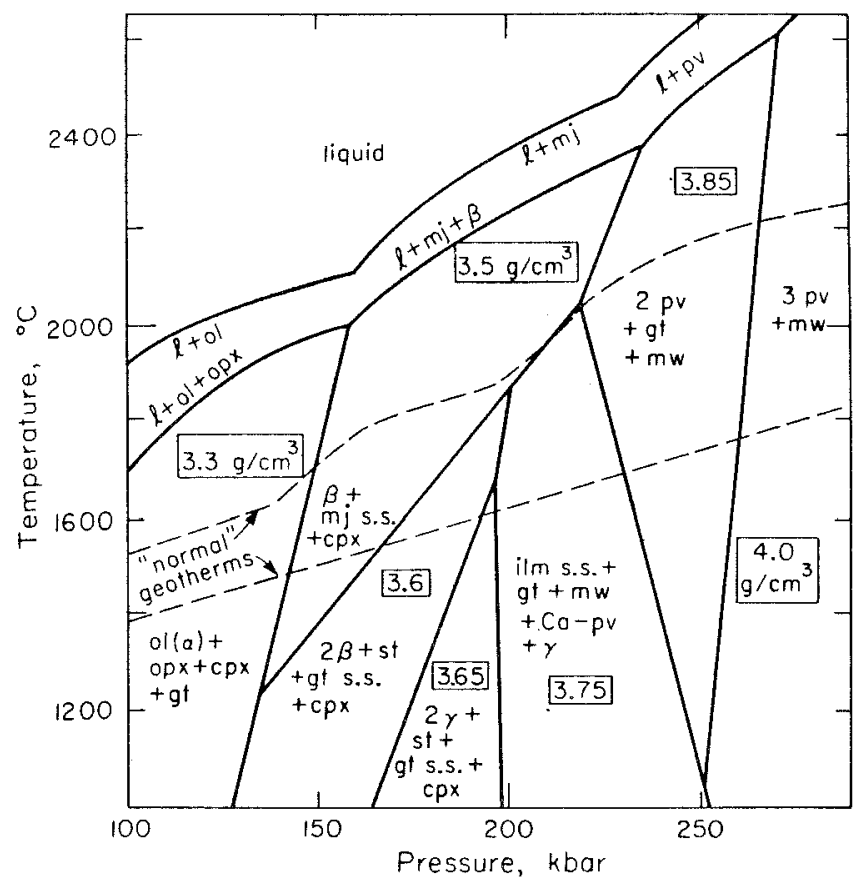

Fig. 3. Provisional facies map in the system $\mathrm{MgO}$ $\mathrm{SiO}_{2}-\mathrm{CaO}-\mathrm{Al}_{2} \mathrm{O}_{3}$ with an ol $>$ opx $>\mathrm{cpx} \sim$ ga mineralogy at low pressure, based on a synthesis of a variety of subsolidus and melting experiments on peridotites. The geotherms bracket most estimates of temperatures in "normal" or average mantle. Warmer parts of the mantle may be near the solidus; the interiors of slabs may be $800^{\circ} \mathrm{C}$ colder. The phase diagram is based on incomplete and sometimes inconsistent reconnaissance experiments and must be taken as provisional until systematic and reversed experiments are performed. Based on experiments and interpretations by Kato and Kumazawa [1985, 1986]; Akaogi and Akimoto [1977], Ohtani et al. [1986, 1987], Kanzaki [1987], Ito and Takahashi [1986], Yamada and Takahashi [1984], Irifune et al. [1986], and Sawamoto [1986]. See also Ito and Naurotsky [1985], Akaogi et al. [1984], Navrotsky et al. [1979], and Kushov and Galimzyanov [1986]. The $2 \beta$ and $2 y$ mean that both $\mathrm{Mg}_{2} \mathrm{SiO}_{4}$ and $\mathrm{MgSiO}_{3}$ have transformed to a spinel assemblage.

with the slab is far from constant with depth. Furthermore, the density anomaly of a slab with respect to the adjacent mantle is quite different from the density contrast between the surface plate and the underlying mantle, as estimated from the bathymetry-age relation for oceanic plates.

The important phase changes in the mantle mostly have Clapeyron slopes that correspond to depth variations of $30-100 \mathrm{~km} / 1000^{\circ} \mathrm{C}$. When solid-solid effects are taken into account, the widths of the phase changes, at constant temperature, are, for example, $40 \mathrm{kbar}$ for complete transformation of $\alpha$ - to $\gamma$-spinel; about $10 \mathrm{kbar}$ for $\alpha-\beta$ and $40 \mathrm{kbar}$ for $\beta-\gamma$. The comparable changes, at constant pressure, occur over a temperature interval of $300^{\circ} \mathrm{C}$, which is less than half the temperature contrast across a subducting slab.

Most high-pressure subsolidus experiments are performed at a few standard temperatures or have large uncertainties in both temperature and pressure or are unreversed. This has made it difficult to assess the effect of temperature on phase boundaries over the whole temperature range of the upper mantle. Most discussions of mantle mineralogy are based on phase equilibria studies at temperatures much lower than those expected in the mantle. Some high-temperature subsolidus information is now available from experiments primarily performed to understand melting relationships. By combining these experiments with theoretical studies based on calori- metric data it is possible to synthesize a provisional facies map for the peridotite system (Figure 3). The main surprise in this synthesis is the extremely limited stability field of $\gamma$-spinel at high temperature. The $\gamma$-spinel has been thought to be the major phase in the transition region because of early experiments by Ringwood and Major [1970] and Akimoto [1972] at relatively low temperature. The stability field of $\gamma$-spinel is squeezed out at high temperature by $\beta$-spinel and ilmenite + magnesiowüstite, and these phases plus majorite are dominant at transition region pressures. The elevation of the spinel and ilmenite boundaries, plus the expansion of the $\gamma$-spinel and stishovite fields, is primarily responsible for the high density and seismic velocity in cold mantle. At low temperatures, $\beta$ - or $\gamma$-spinel plus stishovite replace majorite as dominant phases, and these are denser and faster than majorite. Figure 4 shows zero-pressure densities calculated from Figure 3 for an average "normal" geotherm and a geotherm some $800^{\circ} \mathrm{C}$ colder.

\section{SLABS}

One result of the neglect of isobaric phase changes is the conclusion that density and velocity anomalies in the upper mantle are not sufficient to explain the magnitude of slabrelated geoid and seismic anomalies. Hager [1984] calculated the geoid signal by associating slabs with an average density contrast of $0.1 \mathrm{~g} / \mathrm{cm}^{3}$. This can explain the geoid signal for whole mantle convection models which have large geoiddensity kernels. When phase changes are included, the average density contrast of slabs is about 3 times greater, being about $0.4 \mathrm{~g} / \mathrm{cm}^{3}$ midway through the upper mantle (Figure 4). In chemically layered models the density-geoid response goes to zero at chemical boundaries, and the average value of the upper mantle kernel is much less than for the whole mantle cases. Therefore, for the class of models treated by Hager [1984] a large density contrast is consistent with stratified

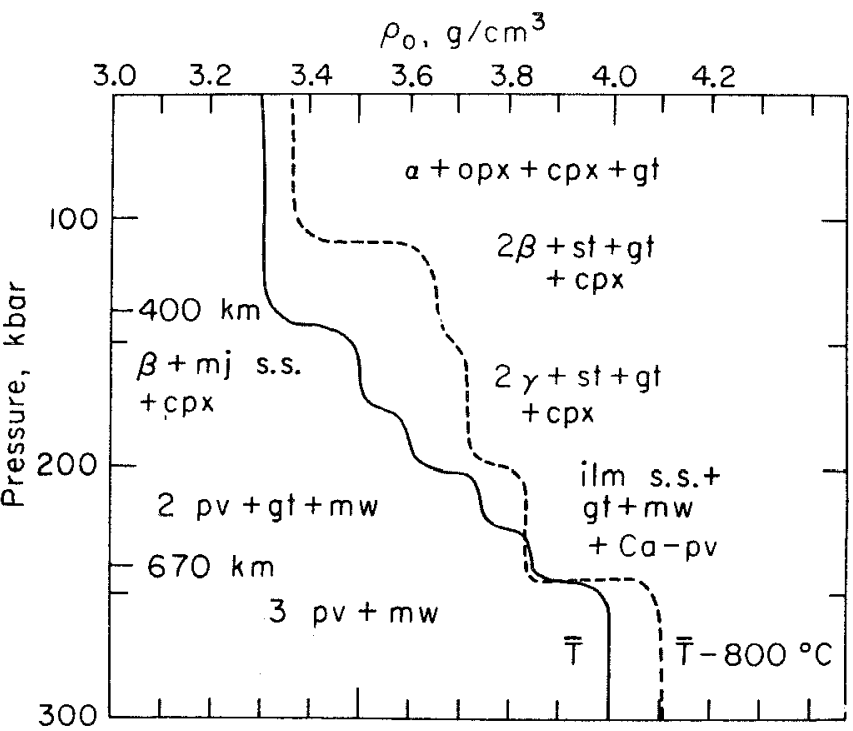

Fig. 4. Zero-pressure density calculated from Figure 3 for peridotite at two temperatures (the mean of the "normal" geotherms and a temperature $800^{\circ} \mathrm{C}$ colder). Phase changes and thermal expansion are included. The density differences would be different for an eclogitic mantle or for a slab which differs in chemistry from the surrounding mantle. Abbreviations are $\alpha$ (olivine), opx (orthopyroxene), cpx (clinopyroxene), gt (garnet), gt s.s. (garnet plus majorite, mj), st (stishovite), $\mathrm{ilm}$ s.s. ( $\mathrm{MgSiO}_{3}$ ilmenite + gt-ilmenite), mw (magnesiowüstite), 1 (liquid). 
convection but not with whole mantle convection. Hager et al. [1981] used a density contrast of $0.067 \mathrm{~g} / \mathrm{cm}^{3}$ in their modeling of slab dips, a study which also favored slab penetration into the lower mantle. A larger density contrast increases slab dips. In addition, H. W. Zhou and R. Clayton (manuscript in preparation, 1987) have shown that slab dips are shallower than the dips of deep earthquake zones.

There are several phase changes in cold subducting material that contribute to the increase in the relative density of the slab. The basalt-eclogite transition is elevated, contributing a $15 \%$ density increase for the basaltic portion of the slab in the upper $60 \mathrm{~km}$ or so. The absence of melt in the slab relative to the surrounding asthenosphere increases the density and velocity anomaly of the slab in the upper $300 \mathrm{~km}$ or so of the mantle. The olivine-spinel and pyroxene-majorite phase changes are elevated by some $100 \mathrm{~km}$ above the $400-\mathrm{km}$ discontinuity, contributing about $10 \%$ to the density contrast in the upper mantle. The $\beta-\gamma$ rransition is also elevated, adding several percent to the density of the slab between 400 and 500 $\mathrm{km}$. The ilmenite form of pyroxene is $5 \%$ denser than garnetite, increasing the density contrast of the cold slab between 500 and $670 \mathrm{~km}$, relative to hot mantle, by about a factor of 2 or 3 over that computed from thermal expansion. In addition to these effects, the formation of a detached thermal boundary layer below the $650-\mathrm{km}$ discontinuity can also increase the total mass anomaly associated with subduction. The latter can increase or decrease the geoid anomaly associated with subduction, depending on the nature of the chemical layering [Richards and Hager, 1984].

The seismic anomaly associated with slabs is also much greater than can be accounted for by the effect of temperature on velocity [Frohlich and Barazangi, 1980]. Phase changes, including partial melting outside the slab, may be the cause. The associated density contrast between slab and normal mantle is greater than between the plate and the underlying mantle as estimated from thermal expansion alone.

The ilmenite form of $\mathrm{MgSiO}_{3}$ is a stable phase, at low temperature, in the lower part of the transition region (Figure 1). Ilmenite is about $8 \%$ denser than garnet-majorite and has a $V_{p}$ about $10 \%$ greater. Although ilmenite is only $4 \%$ slower than perovskite, it is $7 \%$ less dense. IImenite becomes stable at slab temperatures somewhere between 450 and $600 \mathrm{~km}$ and is predicted to remain stable to depths greater than the perovskite phase boundary in higher-temperature mantle. Although the slab is predicted to be locally less dense than the lower mantle at $\sim 650 \mathrm{~km}$, it will probably depress the boundary between the upper and lower mantles because of the accumulated density excess and the negative Clapeyron slope, between ilmenite-spinel and perovskite-MgO. The $\mathrm{CaMgSi}_{2} \mathrm{O}_{6}$ component of the mantle transforms to perovskite at a slightly lower pressure than the comparable transformation in $\mathrm{MgSiO}_{3}$, and the transformation pressure is lower at low temperature. These all contribute to the velocity and density anomaly of the slab at the base of the transition region.

In the discussion so far we have assumed that the slab is identical in composition to the adjacent mantle. The slab is probably laminated. The upper layer is basalt/eclogite, and the second layer is probably olivine-orthopyroxene harzburgite. These undergo their own series of phase changes and, when cold, remain denser than garnet peridotite to at least $500 \mathrm{~km}$.

The composition of the lower oceanic lithosphere is unknown. The alternatives are basalt-depleted peridotite, or harzburgite, undepleted peridotite, and basalt/eclogite. The latter could be the result of underplating of the oceanic lithosphere by melts from the mantle. Cold harzburgite averages about $0.1 \mathrm{~g} / \mathrm{cm}^{3}$ denser than warm pyrolite, between 400 and $600 \mathrm{~km}$ [Ringwood, 1982]. At $600 \mathrm{~km}$ it becomes less dense. Eclogite is denser than peridotite at the same temperature to depths of 500-560 km [Anderson, 1982a, b, c; Anderson and Bass, 1986] and, when cold to $680 \mathrm{~km}$ [Irifune and Ringwood, 1986]. Cold eclogite is about $4-5 \%$ denser than warm peridotite above $550 \mathrm{~km}$ depth. If the $650-\mathrm{km}$ discontinuity is a chemical boundary, this boundary will be depressed by the integrated density excess in overlying cold mantle even if the deeper part of the slab is buoyant. The " $650-\mathrm{km}$ discontinuity" is expected to be an irregular boundary in a chemically stratified mantle and to be much deeper under slabs. In any event, it appears that the different phase assemblages in the slab relative to warm mantle will contribute to the density contrast. An increase of intrinsic density between upper and lower mantle and a negative Clapyron slope will inhibit slab penetration into the lower mantle. Hager [1984] invokes an increase in viscosity at $650 \mathrm{~km}$ to support partially the slab in order to explain the geoid highs associated with subduction zones. A chemical change has a similar effect.

The question of whether eclogite becomes less dense than peridotite at pressures near the base of the transition region and top of the lower mantle has been controversial. Anderson and coworkers [Anderson, 1979a, b, 1981a, b, 1982a, b, c; Anderson and Bass, 1986] have maintained that eclogite becomes less dense than peridotite at the base of the transition region and is less dense than the top of the lower mantle. The primary reason is the large stability interval of garnet. Ringwood and coworkers [Ringwood, 1975, 1982; Irifune et al., 1986] have maintained until recently that eclogite is denser than peridotite at all pressures. Very recently, they were able to extend the pressure range of their experiments [ Irifune and Ringwood, 1986], and they confirm that the densities of eclogite of mid-ocean ridge basalt (MORB) composition and peridotite do indeed intersect near the base of the transition region. Quartz-free eclogites will actually be less dense than they calculate since MORB-eclogite has excess $\mathrm{SiO}_{2}$-stishovite, a very dense component. Irifune and Ringwood [1986] also assume a very high density for $\mathrm{CaSiO}_{3}$-perovskite. The crustal component of the slab, even if it survives subduction to $650 \mathrm{~km}$, does not control its own destiny. It is the integrated density of the slab, the intrinsic density contrast across the $650-\mathrm{km}$ discontinuity, and the PT locations of phase boundaries in the slab and lower mantle that determine whether slabs will be able to sink into the lower mantle. In a chemically layered mantle the " $650-\mathrm{km}$ " discontinuity will be depressed by the subducted slab, and therefore, in this sense, the upper mantle protrudes into the lower mantle or, more precisely, protrudes below the depth usually assigned to the upper mantle-lower mantle boundary. Whether it can protrude deeply enough to be entrained in lower mantle flow or to overcome the negative Clapyron slope or whether, even in this case, it can become denser than the lower mantle, are questions which have yet to be completely addressed. The seismic problem of determining whether slabs are continuous across the upper-lower mantle boundary (the depressed " $650-\mathrm{km}$ " discontinuity) is complicated by the likely presence of a detached thermal boundary layer at the top of the lower mantle under such conditions. This would be dense and fast and would be hard to distinguish from a penetrating 
slab. In this regard, the complete lack of seismicity below $\sim 690 \mathrm{~km}$ and the apparent crumpling of the slab [Giardini and Woodhouse, 1984, 1986] near this depth are significant.

In peridotite the density in the lower part of the transition region is dominated by $\beta$-spinel $\left(\rho_{0}=3.47 \mathrm{~g} / \mathrm{cm}^{3}\right)$ or $\gamma$-spinel $\left(3.56 \mathrm{~g} / \mathrm{cm}^{3}\right)$ and majorite $\left(3.52 \mathrm{~g} / \mathrm{cm}^{3}\right)$ or ilmenite $\left(3.82 \mathrm{~g} / \mathrm{cm}^{3}\right)$. In eclogite the mineralogy is garnet $\left(3.56 \mathrm{~g} / \mathrm{cm}^{3}\right)$, Caperovskite $\left(\sim 4.1 \mathrm{~g} / \mathrm{cm}^{3}\right)$, and possibly $\mathrm{Al}_{2} \mathrm{O}_{3}(3.99 \mathrm{~g} / \mathrm{cm})$ and $\mathrm{MgO}\left(3.58 \mathrm{~g} / \mathrm{cm}^{3}\right)$. An eclogitic slab will therefore have a density between about $4 \mathrm{~g} / \mathrm{cm}^{3}\left(\mathrm{Ca}\right.$-perovskite $\left.+\mathrm{Al}_{2} \mathrm{O}_{3}\right)$ and 3.56 $\mathrm{g} / \mathrm{cm}^{3}$ (garnet) which is less than the uncompressed density of the lower mantle [Butler and Anderson, 1978]. Therefore neither harzburgite nor eclogite have densities high enough to sink into the lower mantle, and we expect a barrier to slab penetration and thickening and lateral flow of subducted material at the base of the transition region. A large jump in viscosity near $650 \mathrm{~km}$ [Hager, 1984] also provides a barrier to slab penetration, but in a chemically homogeneous mantle, upper mantle material eventually circulates into the lower mantle. In either case, the slab does not slide easily into the lower mantle, as implied in the thermal models of Creager and Jordan [1984]. The high density of the slab, relative to adjacent mantle, contributes to the geoid and seismic velocity anomalies associated with subduction zones and, in general, will increase their dips compared to strictly thermal models of the slab.

There is little information on the variation in depth of the $650-\mathrm{km}$ discontinuity, but it is unlikely to vary by more than $100 \mathrm{~km}$ from its mean depth. A determination of the actual depth of the discontinuity under slabs will constrain the integrated density contrast of the slab and the nature of the boundary. An interesting question is whether the average composition of the slab is the same as the surrounding mantle as assumed in most discussions. An eclogitic slab, for example, sinking through a peridotitic mantle would cause a smaller depression of a chemical interface at $650 \mathrm{~km}$ than would a peridotitic slab.

\section{GEOID MODELING}

The geoid exhibits broad highs encompassing most of South America, Central America, western North America, Alaska, Aleutians, Kamchatcha, Kuriles, Philippine Sea plate, Borneo, New Guinea, Tonga, Fiji, New Zealand, and the Mediterranean, regions of current or recent subduction. The surface wave solutions for the mantle below $350 \mathrm{~km}$, and extending through the transition region, are fast for most of these regions, indicating broad regions of anomalously fast, and presumably cold and dense, material [Nataf et al., 1986]. Narrow slabs would not show up because of the wavelengths and lateral sampling of surface waves. This suggests that much more than about $100 \mathrm{~km}$ of dense material in the vicinity of intermediate and deep focus earthquakes contributes to the geoid. In this regard it is pertinent that in regionalized surface wave inversions, old oceans, generally adjacent to subduction zones, and trench-marginal sea regions have high seismic wave velocities in the transition region [Nataf et al., 1986] consistent with material piling up or spreading laterally at the base of the upper mantle.

The intermediate wavelength geoid, $l=49$, shows an excellent correlation with the location of subducted slabs [Hager, 1984]. Hager [1984], Richards and Hager [1984], and Richards [1986] calculate a variety of convective models and conclude that the slab-correlated geoid is best explained by whole mantle convection with slab penetration into the lower mantle. They assume a density contrast, due to thermal expansion, of about $2 \%$ and roughly independent of depth. This corresponds to a coefficient of thermal expansion of $3 \times 10^{-5}$ ${ }^{0} \mathrm{C}^{-1}$, a value appropriate for low-pressure minerals at low temperature and pressure. With these assumptions the layered connection models with slabs confined to the upper mantle explain the pattern of the geoid but underestimate the amplitude of the geoid anomaly by a factor of $3-5$. If chemically stratified mantle convection is to be reconciled with the amplitudes as well as the pattern of geoid anomalies associated with subduction zones, the mass anomalies must be 3-5 times larger than used in the calculations. The considerations of this paper show that temperature-induced phase changes provide this amount of integrated density excess. In fact, for layered convection the kernels relating density excess to geoid anomaly peak at about $300-500 \mathrm{~km}$ depth [Richards and Hager, 1984]. This is just where the temperature-induced phase changes have their maximum amplitude and therefore the maximum effect on the geoid.

The elevation of phase boundaries in the cold slab plus the introduction of new assemblages gives slab densities about $5-11 \%$ greater than normal mantle between 350 and $550 \mathrm{~km}$. The predicted slab anomaly is more than $10 \%$ near 420 . These density excesses are considerably greater than due to thermal expansion alone. The geoid anomalies associated with subducted slabs are therefore much greater than previously supposed. The density-geoid kernels are about a factor of 3-5 less for chemically stratified flow than for whole mantle flow, and this is about the required factor.

One concludes therefore that layered mantle convection with slabs confined to the upper mantle provides a better fit to the geoid data since geoid anomalies would be overestimated with whole mantle convection kernels and dense slabs penetrating into the lower mantle.

Shields and mid-ocean ridges show little correlation with the long-wavelength geoid, in spite of their prominence in upper mantle tomographic maps. This is due to a combination of circumstances. Lower mantle density variations dominate the long-wavelength $(l=2,3)$ geoid [e.g., Hager and Clayton, 1987]. Density variations of small radial or lateral extent, or near the surface and chemical boundaries, have little effect on the long-wavelength geoid. Surface wave tomographic maps and upper mantle structures derived from them show litule correlation with the geoid except near $l=5,6$ and the coincidence of the slower regions of the upper mantie and intermediate-wavelength geoid highs. Some of the prominent velocity anomalies of the shallow mantle (shields fast, back arc basins slow) reverse sign at depth, and some ridges are last below $400 \mathrm{~km}$. There is therefore some cancellation of the geoid signal. Shields have thick, low-density crusts, giving a positive isostatic geoid signal, but the high velocities below $200 \mathrm{~km}$, if accompanied by high density, give a negative geoid signal. Shields, on average, are slow below $400 \mathrm{~km}[$ Nalaf et al., 1986]. Young oceans, however, on average, are slow throughout the upper mantle, but they also are not evident in the geoid. Density anomalies in the upper mantle have less effect on the geoid if there is a chemical contrast between the upper and lower mantle than if the mantle is uniform in composition [Hager, 1984]. Therefore one should not be surprised by the general lack of correlation of the geoid with surface tectonics, particularly if there is a chemical discontinuity near $650 \mathrm{~km}$ depth. Some of the tomographic features may also be 


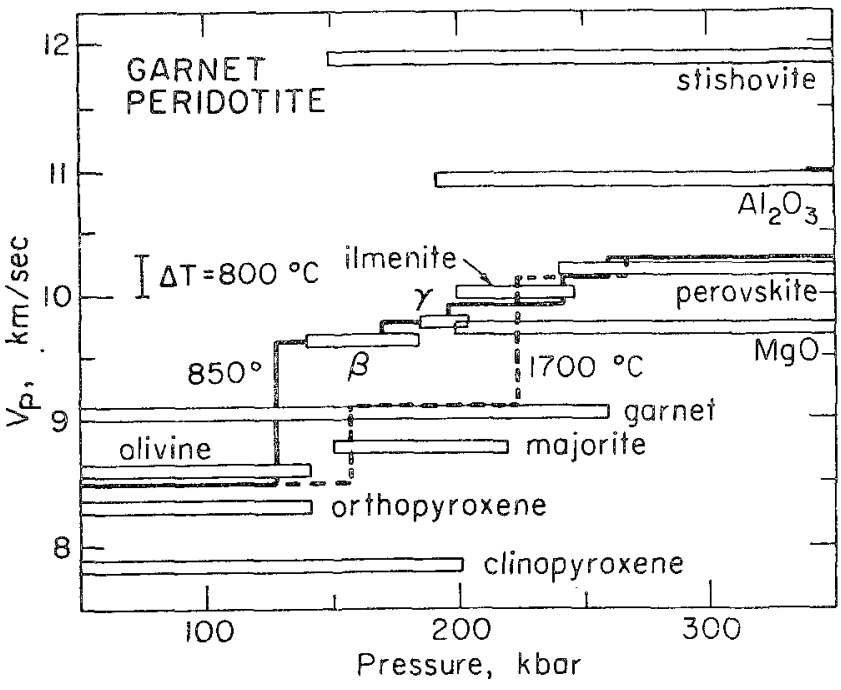

Fig. 5. Compressional velocities, at standard conditions, and stability fields of mantle minerals. The approximate velocity of garnet peridotite, at standard conditions $(P=0, T \sim 20 \mathrm{C})$ for phases stable at two temperatures $(850 \mathrm{C}, 1700 \mathrm{C})$ is also shown. The small bar gives the approximate change in $V_{n}$ for an 800 C change in temperature $\left(\partial V_{p} / \partial T=-4.1 \times 10^{-4} \mathrm{~km} / \mathrm{s}\right.$ " C).

due to lateral variations in anisotropy, or crystal orientation, with no associated density variations.

\section{Slab Velocity Anomalies}

Velocity anomalies associated with slabs are about $+4 \%$ at $50 \mathrm{~km},+10 \%$ at $100 \mathrm{~km},+3$ to $+10 \%$ from 200 to $300 \mathrm{~km}$, +4 to $7 \%$ at $400 \mathrm{~km},+2$ to $5 \%$ at $450 \mathrm{~km},+4$ to $5 \%$ at 500 $\mathrm{km},+12 \pm 4 \%$ at $620 \mathrm{~km},+9 \pm 3 \%$ at $650 \mathrm{~km}$, and $+8 \pm 2 \%$ between 580 and $660 \mathrm{~km}$ [Engdahl and Gubbins, this issue; Fitch, 1975; Hirahara, 1977; Huppert and Frohlich, 1981; Bock, 1981]. A $\triangle T$ of $800^{\circ} \mathrm{C}$ and a velocity contrast of $6 \%$ imply that $\hat{o} V_{p} / \partial \mathrm{T}=-6.4 \times 10^{-4} \mathrm{~km} / \mathrm{s}{ }^{\circ} \mathrm{C}$. A $12 \%$ velocity contrasi doubles this figure. Allowing for the averaging of seismic waves across the temperature gradient would also raise the implied temperature derivatives. The values of $\partial V_{p}$ $/ \partial T$ for $\mathrm{MgO}, \mathrm{Al}_{2} \mathrm{O}_{3}$, olivine, spinel, and garnets fall in the range -3 to $-5.2 \times 10^{-4} \mathrm{~km} / \mathrm{s}{ }^{\circ} \mathrm{C}$ [Anderson et al., 1968] which are less than the values implied by the seismic data for a purely thermal effect. Furthermore, temperature derivatives are expected to decrease rapidly with pressure [Anderson, 1987a]. Changes in phase or composition from "normal" mantle are therefore implied since purely thermal effects are sma11. Thus both the phase equilibria calculations and the seismic data support the presence of isobaric phase changes across the slab.

Seismic velocity differences between low-pressure assemblages involving olivine and orthopyroxene and high-pressure assemblages involving $\beta$ - and $\gamma$-spinel and majorite or stishovite are of the order of $10 \%$, and these transitions are expected to be elevated in the cold slab by $100-150 \mathrm{~km}$. Therefore the slab velocity anomaly should be particularly large between about 300 and $400 \mathrm{~km}$. The observed velocity contrast is smaller than the temperature plus phase change effect in an olivine-orthopyroxene mantle, suggesting that there is about $50 \%$ of "inert" component in the slab, material which does not transform over this pressure interval. Garnet is stable to about $600 \mathrm{~km}$ and clinopyroxene (diopside \pm jadeite) is stable to about $500 \mathrm{~km}$. The implication is that the slab is garnet- clinopyroxene (diopside \pm jadeite) is stable to about $500 \mathrm{~km}$. The implication is that the slab is garnet-clinopyroxene-rich relative to most garnet peridotite samples from the shallow mantle. The possibility that the average composition of the slab is not the same as the average composition of the upper mantle complicates the interpretation of slab anomalies and the calculation of the depression of chemical discontinuities by subducted slabs.

The observed slab anomalies are comparable to and greater than the velocity jumps associated with mantle discontinuities. This strongly suggests that lateral velocity changes in the mantle, particularly near subducted slabs, involve isobaric phase changes as well as temperature variations. The velocity jump at the $400-\mathrm{km}$ discontinuity is about $4-5 \%$. This also suggests that garnet and clinopyroxene are important components of the mantle near $400 \mathrm{~km}$. Otherwise the velocity jump would be much greater.

The high gradient in seismic velocity between about 400 and $600 \mathrm{~km}$ depth implies a gradual phase change or series of phase changes occurring over this depth interval. The candidates are majorite to $\beta+$ st, $\beta$ to $\gamma, \hat{\gamma}+$ st to ilmenite, and clinopyroxene to garnet or perovskite. The increase of the slab seismic anomaly below about $500 \mathrm{~km}$ is consistent with major isobaric phase changes occurring below this depth.

The measured or estimated compressional velocitics of the important phases of upper mantle minerals are shown in Figure 5. Also shown are the estimated velocities for peridotite at two temperatures, taking into account the different stable phase assemblages. The major differences occur between about 130 and $225 \mathrm{kbar}$. The heavy lines show the approximate stability pressure range for the various phases. Garnet and clinopyroxene represent less than $20 \%$ of the chosen peridotite composition. Since these minerals are stable to about 260 and $200 \mathrm{kbar}$, respectively, the effect of density and velocity changes associated with phase changes as both a function of temperature and pressure will be lower for a less olivine- and orthopyroxene-rich mantie. The deformation of the $650-\mathrm{km}$ discontinuity, if this is a chemical boundary, will also be less.

Creager and Jordan [1986] used intermediate depth earthquakes (149 and $256 \mathrm{~km})$ to calibrate the effect of the underlying slab on travel times of deeper focus earthquakes. It is clear from Figure 5 that the velocity anomaly below intermediate depth events is not similar to that expected below the deeper events ( 585 and $624 \mathrm{~km}$ ) used in their analysis. These depths correspond to pressures of $200-220 \mathrm{kbar}$. Not only are the average velocity contrasts different but the anisotropies of the stable phase assemblages are also quite different. Any degree of preferred orientation in the slab and the adjacent mantle will affect the differential travel times of rays leaving the source in different directions. A more direct determination of velocity anomalies in the vicinity of intermediate depth earthquakes is about $5-6 \%$ [Engdahl and Gubbins, this issue]. The velocity anomaly in the vicinity of deep focus earthquakes appears to be much greater [Fitch, 1975], in agreement with the above expectations. There is a direct trade-off between the magnitude of the velocity contrast in the vicinity of deep focus earthquakes and normal mantle and the depth extent of the slab beneath these earthquakes in the interpretation of residual sphere anomalies [Jordan, 1977]. A 10\% velocity contrast and a slab extending only $100 \mathrm{~km}$ beneath the source give a travel time anomaly of $1.5 \mathrm{~s}$ for rays sweeping out a cone of $45^{\circ}$ to the plane of the slab. This is about the range of travel time anomalies observed Creager and Jordan [1986]. 
The smaller velocity anomalies assumed by Creager and Jordan [1986] require much deeper slab penetration. Creager and Jordan [1984] assumed a contrast of $10 \%$, but their calculations are obviously in error since their deep slab model predicts $\sim 8$ s anomalies, much greater than observed. Their results, when corrected, are consistent with a short slab.

The small bar in Figure 5 shows a typical change of $V_{p}$ for an $800^{\circ} \mathrm{C}$ temperature change, assuming no phase changes. Note that the effect of the more important phase changes is to double or triple the effect of temperature. The largest effects occur between about 130 and $230 \mathrm{kbar}$, the pressure range of deep focus earthquakcs. Notc that clinopyroxene and garnet, minor constituents of peridotite and pyrolite but major components of eclogitc and piclogite [Anderson and Bass, 1984], have the largest stability fields of low-pressure minerals. The presence of clinopyroxene and garnet reduce the size of the phase change eflects in the upper part of the transition region, particularly near $400 \mathrm{~km}$. The smallness of the velocity jump near $400 \mathrm{~km}$, both radially [Grand and Helmberger, 1984] and lateraily [Engdahl and Gubbins, this issue], indicates the presence of substantial amounts of a "neutral" component (i.e., garnet and clinopyroxene) near this depth. Thesc are the dominant minerals in eclogite. On the other hand, eclogite experiences major transformations and velocity increases between 200 and $250 \mathrm{kbar}$, a pressure range pertinent to the velocity anomaly near deep focus earthquakes.

\section{AnISOTROPY}

For a given crystal structure, or mineral asscmblage, a change in temperature or composition has a relatively small effect on seismic velocity. Changes in mineralogy or crystal orientation have relatively large effects. A phase change affects the density, the average seismic velocity, and the seismic anisotropy or dependence of velocity on direction. The most anisotropic minerals of the upper mantle are olivine, orthopyroxene, $\beta$-spinel, and ilmenite. Anisotropic minerals are likely to be oriented by flow, stress, and recrystallization. Metamorphic and igneous terrains commonly display a regional fabric which is reflected in the preferred orientation, over large areas, of the constituent minerals. In the mantle this preferred orientation manifests itself in seismic anisotropy. This greatly complicates the interpreation of seismic data, particularly for waves traveling in the plane of a subducted slab, since fast in-plane velocities give a similar seismic signature as a fast isotropic slab.

The oceanic lithosphere is markedly anisotropic with fast compressional velocities in the spreading direction. The aximuthal range of velocity, $\sim 6 \%$, is comparable to the phase change effect and is much greater than thermal effects. The interpretation of this anisotropy in terms of oriented olivine and orthopyroxene predicts that velocities in the plane of the plate are higher than normal to the plate. Recrystallization to denser phases probably retains the fast in-plane character of seismic waves in the slab. Velocity variations due to anisotropy and phase changes are generally much greater than those due to temperature and chemistry. Seismic mapping of the slab at depth utilizes waves which travel along the slab, and therefore considerable time advances can occur relative to waves which exit the slab early. Residual sphere analyses of travel time residuals generally show a band of fast arrivals along the trend of the slab [Davies and McKenzie, 1969; McKenzie and Julian, 1971]. The interpretation of these anomalies (the "residual sphere") in terms of velocity and extent of the slab is nonunique. There is a trade-off between velocity contrast, length of slab, and anisotropy. The very young slab subducted under Oregon and Washington gives fast velocities along the trend of the slab [McKenzie and Julian, 1971] even though it should be fairly thin and slow. Thick, cold lithosphere gives similar anomalies, suggesting that anisoiropy may be at least partially responsible for the slab anomaly as mapped on the redsidual sphere. The shear wave splitting observed from deep focus earthquakes [Ando, 1984] may be a manifestation of this near source anisotropy.

Creager and Jordan [1984] use the orientation of magnetic lineations on the Pacific plate and ultrasonic measurements on ophiolites to argue against the presence of anisotropy in the vicinity of deep focus earthquakes. Olivine and orthopyroxene, the main minerals responsible for anisotropy in the oceanic lithosphere, are not stable below $400 \mathrm{~km}$, and their anisotropy and orientation are not relevant to deep slab properties. The low $S$ wave anisotropy of olivine-rich aggregates, also used to argue against slab anisotropy, is not a characteristic of all minerals. The recrystallization of olivine to $\beta$-spinel and then to $\gamma$-spinel and the recrystallization of orthopyroxene to spinel plas stishovite and then to ilmenite at high pressure and low temperature is not expected to lead to randomly oriented isotropic aggregates in the high shear stress slab enviromment. The $S$ wave anisotropy of $\beta$ - and $\gamma$-spinel are, respectively, about 20 and $10 \%$. Tlmenite has a remarkable $S$ wave anisotropy of $26 \%$ [Weidner, 1985]. The fastest, or first arriving $S$ wave, near the symmetry plane of ilmenite has a variation with angle from the symmetry plane that parallels the $P$ velocity variation but is a factor of $3 \frac{1}{2}$ higher. This is just the characteristic, not shared by olivine, that is required to explain the residual sphere data [Creager and Jordan, 1984] from deep focus earthquakes. Creager and Jordan [1984] found that the ratio of the $S$ wave to the $P$ wave residuals averages about $3.5: 1$ but concluded, on the basis of (invalid) comparisons with the shallow oceanic lithosphere, that the evidence for anisotropy is nil. The SCS polarization anisotropy ( $S$ wave splitting) from deep focus earthquakes [Ando, 1984] may be evidence for anisotropy of the deep slab.

The limited data available show that high-pressure recrystallization of olivine and shearing of spinel leads to preferred orientation of spinel [Hamaya and Akimoto, 1982; Fujimura, 1984]. It is difficult to imagine how the minerals, under the stress conditions in the slab, can avoid having a strong preferred orientation. Metamorphic rocks and ice sheets provide abundant evidence for fabrics associated with strong-crystal alignments caused by recrystallization. Calcite (in marble) and ice are easily oriented and these have crystal structures similar to ilmenite. The doep slab is a metamorphic rock par excellence, having undergone about five phase changes under extreme conditions of temperature, pressure, and stress.

Drastic changes in mincralogy with relatively small changes in temperature are well known in metamorphic petrology. Metamorphic terrains also exhibit pronounced microscopic and large scale fabric or anisotropy. The cold slab can be viewed as a low-temperature, high-pressure metamorphic assemblage with high-density, high seismic velocity phases compared to normal mantle or high-temperature mantle. At high pressure, the low-temperature assemblages include more $\beta$ and $\gamma$-spinel, stishovite, magnesiowüstite, and ilmenite than higher-temperature assemblages. Olivine and orthopyroxene have broader stability fields at high temperature and moderate 
pressure while majorite, garnet, and perovskite have broader high-temperature stability fields at high pressure. It is worth noting that $\beta$-spinel and ilmenite are markedly more anisotropic than garnet and, probably, majorite, and we can expect the deep slab to be analogous to other "low-grade" metamorphic terrains in having a strain-induced fabric or anisotropy.

Anisotropy is now known to be a pervasive feature of the upper mantle [e.g., Nataf et al., 1986; Tanimoto and Anderson, 1985; Hirahara and Ishikawa, 1984]. Neglect of anisotropy has also contributed to the controversy regarding the depth of continental roots [Anderson, 1979c]. Most of the travel time difference between oceans and continents occurs above 250 $\mathrm{km}$. Some of this may be due to variations in anisotropy, a large effect in the shallow mantle [Nataf et al., 1986].

\section{Long-WaVelength Velocity AnOMalies}

The most pronounced long-wavelength lateral seismic anomalies are the differences between stable shields on the one hand and tectonic and young oceanic regions on the other [Anderson, 1967a; Nataf et al., 1986; Grand and Helmberger, 1984]. Shields are extremely fast in the upper $150 \mathrm{~km}$, an observation that has been explained in terms of a cold, forsterite-rich shield lithosphere extending to about this depth [Anderson and Bass, 1984]. The high velocities, but low gradients, below $150 \mathrm{~km}$, have been explained in terms of adiabatic compression along a $1400^{\circ} \mathrm{C}$ adiabat [Anderson and Bass, 1984]. The negative subshield velocity gradients between 150 and $200 \mathrm{~km}$ imply a high thermal gradient and, probably, a change in mineralogy. This is consistent with petrological evidence from nodules and pyroxene geotherms [Basu et al., 1986]. This plus the ease of flow of mantle silicates at these temperatures and the viscosity found from postglacial rebound studies suggest that shield mantle below $200 \mathrm{~km}$ is participating in mantle convection rather than being a conductive boundary layer attached to the overlying plate. Partial melting can cause large decreases in seismic velocity with little change in density. This is a useful property since neither young oceans nor shields are particularly evident in the longwavelength geoid, but they are obvious features in surface wave tomographic maps of the upper mantle [Nakanishi and Anderson, 1984a, b; Woodhouse and Dziewonski, 1984; Nataf et al., 1984, 1986; Tanimoto and Anderson, 1985]. The deep continental tectosphere hypothesis focuses on the high velocities associated with shields ("roots") instead of the low velocities associated with oceans and tectonic regions. If one attempts to explain the relatively large velocity range in the upper mantle without invoking partial melting and other temperature-induced phase changes, one would be forced to conclude that large temperature and chemical differences extend to a depth of about $400 \mathrm{~km}$. A slight increase in temperature, however, from the $1400^{\circ} \mathrm{C}$ shield adiabat results in a significant deepening of the olivine plus orthopyroxene stability field, a broadening of the garnet-majorite stability field and a likely intersection of the solidus with the geotherm. All of these effects serve to decrease the velocity and density of warm mantle at depths shallower than about $400 \mathrm{~km}$, and to generate long-wavelength tomographic anomalies with no requirement for large lateral variations in temperature and composition as required in the tectosphere, deep continental root, hypothesis. The density contrast caused by changes in chemistry, as, for example, between fertile and depleted peridotite is only about $2 \%$; the velocity contrast is less than $1 \%$ [Jordan, 1979]. Therefore reasonable changes in temperature and chemistry have much smaller effects than isobaric phase changes and variations in crystal orientation.

The hypothesis that the subshield mantle is depleted in a basaltic component [Anderson and Kovach, 1964; Anderson, 1967a; Toksöz et al., 1967; Jordan, 1978] seems to apply to the upper $150 \mathrm{~km}$ under shields [Anderson and Bass, 1984; Boyd and Mertzman, 1987] but not necessarily to greater depths. The "cold" $1400^{\circ} \mathrm{C}$ shield abiabat is higher than the $1300^{\circ} \mathrm{C}$ adiabat previously assumed for "hot" oceanic mantle [Jordan, 1975], and only a minor temperature perturbation is required to partially melt subshield mantle, causing a substantial reduction in velocity. Whether the removal of a basaltic fraction increases or decreases, the density and velocity of the residue depend on the depth and the relative fractions of garnet (high velocity, high density) and clinopyroxene (low velocity, low density) which are removed. The high velocities and low $V_{p} / V_{s}$ of the upper $\sim 120 \mathrm{~km}$ of the shield mantle are consistent with a refractory chemistry (forsteritic olivine and orthopyroxene) that is intrinsically less dense than garnet-rich peridotite or pyrolite [Anderson and Bass, 1984]. To depths of about $300 \mathrm{~km}$ under oceanic and tectonic regions the velocities are less than any plausible mineralogy, strongly suggesting the presence of a partial melt phase. This and other isobaric phase changes have such a large effect below $200 \mathrm{~km}$ that it is difficult to argue for the presence of second order effects such as a lateral change in chemistry. There is, as yet, no geophysical evidence for chemically distinct roots for shields extending deeper than $150-200 \mathrm{~km}$ depth.

\section{SlaB DiPS}

We have addressed two of the observations that have been used to argue for deep slab penetration and whole mantle convection, namely, the geoid and travel time anomalies associated with subduction zones. The neglect of isobaric phase changes has led to an underestimate of the density and velocity contrast associated with slabs.

Another argument is based on the dips of subduction zones [Hager and O'Connell, 1978]. Using kinematic plate motions, these authors show that the trends of deep seismicity parallel the flow lines for whole mantle convection models. The dip of Tonga-Fiji was particularly discrepant with upper mantle flow models. The study of Giardini and Woodhouse [1984, 1986] suggests a strong resistance to subduction at $\sim 650 \mathrm{~km}$ for the Tonga-Fiji area, with evidence for slab thickening and lateral motion at the depth of the deepest earthquakes. One possible explanation for this discrepancy is the existence of strong lowvelocity anomalies in the upper mantle near Tonga-Fiji and the central Pacific [Nakanishi and Anderson, 1984a, $b ;$ Nataf et al., 1984, 1986; Woodhouse and Dziewonski, 1984]. These anomalies are similar to those at mid-ocean ridges and may provide a component of mantle flow not included in the kinematic calculation. There are also strong negative lower mantle anomalies in the central and southern Pacific [Hager and Clayton, 1987] which may affect the flow near the base of the slab which can affect its dip. Finally, the deformation of the upper mantle-lower mantle boundary and the increased density of the slab may affect the dip. From the results of Hager et al. [1981] it appears that an increased slab density will satisfy the dips of subduction zones, for an upper mantle flow model, in New Hebrides, Japan, Kuriles, Aleutians, Chile, and Mariannas. It is also possible that the trends of deep focus earthquakes do not parallel the dips of the high-density, highvelocity subducting material (H. W. Zhou and R. Clayton, 
manuscript in preparation, 1987). These conjectures cannot replace detailed calculations of the effects of these neglected phenomena.

Although the shallow slab is generally denser than the surrounding mantle, it may become less dense than surrounding mantle when the former has transformed to a perovskite-rich assemblage while the former is still in the ilmenite or majoritegarnet field. The harzburgite portion of the slab is also less dense than surrounding mantle, particularly when it warms up. The negative buoyancy at the base of the slab will probably affect the dip. The deeper part of the slab has little effect on the geoid in a chemically stratified mantle because the density-geoid kernal goes to zero at the boundary [Richards and Hager, 1984; Hager, 1984]. The reversal of the density anomaly in the deep slab is evident in the calculations of Anderson and Bass [1984], Irifune and Ringwood [1986], and Ringwood [1982] and is also implied by the negative Clapeyron slope of ilmenite-perovskite and $\gamma$-spinelperovskite $+\mathrm{MgO} \quad[$ Ito and Yamada, 1982]. Although $\mathrm{MgSiO}_{3}$-ilmenite is less dense than perovskite, it has similar elastic properties. Perovskite and ilmenite have the same Si coordination but different $\mathrm{Mg}$ coordinations and $\mathrm{Mg}-\mathrm{O}$ and $\mathrm{O}-\mathrm{O}$ distances. The shorter $\mathrm{Mg}-\mathrm{O}$ distances in ilmenite cause an increase in this part of the repulsive potential and hence a relatively high modulus. The greater $\mathrm{O}-\mathrm{O}$ distances cause the density to be less. Thus the deepest portions of the slab can be fast (comparable in velocity to the lower mantle, Figure 5) but buoyant (Figure 4). The possible buoyancy of the deeper parts of the slab will decrease the size of the depression of a chemical boundary between the upper and lower mantle.

\section{Conclusions}

Lateral variations in temperature and composition have relatively small effects on density and seismic wave velocities. Temperature changes at constant depth are accompanied by isobaric phase transitions just as pressure changes at constant temperature, or along an adiabat, are accompanied by pressure-induced phase changes. The increase of density over the width of a slab is $3-4$ times larger than that due to thermal expansion alone. There is a corresponding increase in seismic velocity. The stability field of $\gamma$-spinel is greatly expanded at low temperature, and this contributes to the density and velocity anomaly of the deeper portions of the slab. In the eclogite portion of the slab the transformation of clinopyroxene to a dense Ca-rich phase, possibly perovskite, also contributes to these anomalies. In view of these deep phase changes, and their sensitivity to temperature changes, one cannot assume that the variation of physical properties is due to temperature alone, the basic premise of the deep slab penetration hypothesis.

The ilmenite form of pyroxene is the fastest upper mantle mineral, and it is stable over a broad depth interval in the cold slab environment. The presence of ilmenite and $\gamma$-spinel in the slab below about $500 \mathrm{~km}$ obviates the need to invoke deep aseismic extension of the slab into the lower mantle to explain deep focus earthquake velocity anomalies. The lowtemperature, high-density phase assemblages ( $\gamma$-spinel, ilmenite, Ca-perovskite, stishovite) in the slab also remove the discrepancy between slab-related geoid anomalies and thermal models of slabs confined to the upper mantle.

The role of pressure-induced phase changes in the radial structure of the mantle is well known. Horizontal variations in temperature affect the depths of these phase changes and cause lateral variations in velocity and density which are comparable to vertical variations. Thus the olivine-spinel phase changes are elevated in cold slabs and partial melting occurs in the hotter regions of the mantle. The "cold" $1400^{\circ} \mathrm{C}$ shield adiabat, in fact, is not far from the solidus of peridotite. New mineral assemblages occur in parts of the mantle exhibiting extremes in temperature, assemblages that do not just represent elevations or depressions of phase boundaries that occur at different depths in "normal" mantle. The "normal" highpressure form of pyroxene and garnet is garnetite, a solid solution of majorite and garnet. This coexists with the $\gamma$-spinel form of olivine under normal conditions in the bottom half of the transition region, about $500-650 \mathrm{~km}$. At lower temperatures the stable form of a pyroxene-garnet assemblage is "ilmenite" solid solution or ilmenitite. In several deep seismic zones there is an increase in dip near $500 \mathrm{~km}$ and a change in the level of seismicity. There is also some evidence that the velocity contrast between the slab and normal mantle increases near this depth. A number of studies have given a velocity contrast of about 3-5\% from 400 to $500 \mathrm{~km}$. Fitch [1975] determined values of $5-10 \%$ below $500 \mathrm{~km}$.

The considerations of this paper show that the density anomalies associated with slabs have been grossly underestimated because isobaric phase changes have been ignored. With the new density models the geoid anomalies associated with whole mantle convection models may be too large even without the conjectured aseismic extensions of the slab into the lower mantle. The difference, if any, between the density anomalies calculated here and the factor of 3-5 required by Hager [1984] and Hager and Clayton [1987] if slabs cannot sink into the lower mantle can probably be accommodated by aseismic slabs, or lateral flow, at the base of the transition region.

The long-wavelength tomographic anomalies in the upper mantie are consistent with tectonic regionalizations and heat flow. The lateral differences appear to be due to the presence of partial melt in the slow regions and other phase changes rather than to a chemically distinct continental root extending to depths in excess of $400 \mathrm{~km}$. The partial melt explanation of the pronounced low-velocity zone under oceans and tectonic regions is another example of a new phase, partial melt, entering the system under extremes of temperature, a phase that does not exist in colder (shield) mantle. Chemical and temperature effects are much less important than phase changes. Hot regions of the mantle may also be slower because of the exsolution of garnet at low pressure and the depression of the olivine-spinel phase boundary and the expansion of the garnet-majorite stability field at high pressure.

A "thick" chemically distinct continental shield lithosphere of about $150-200 \mathrm{~km}$ in thickness floating about on a laterally heterogeneous (in temperature and phase) mantle is consistent with the rapid drop in shear velocity below $150 \mathrm{~km}$, the inferred adiabatic gradient between 200 and $400 \mathrm{~km}$, the petrological discontinuity and kinked geotherm near $150 \mathrm{~km}$ inferred from mantle xenoliths [Boyd, 1987; Basu et al., 1986; Boyd and Mertzman, 1987], and the absence of a pronounced shield geoid signature. Continents can affect the temperature in the underlying mantle. Large stationary continents can insulate the underlying mantle by acting as conductive boundary layers [Anderson, 1982b] and by preventing subduction of cold oceanic lithosphere. They therefore, over the long term, generate hotter than average mantle which affects convection which in turn breaks up or moves the continent. Moving con- 
tinents, on the other hand, override cold oceanic lithosphere which gives a cool subcontinental mantle. Drifting continents also tend to move away from hot regions and toward cold regions of the mantle. The present epoch, characterized by relatively cold subshield mantle, may represent the end of a period of continental dispersal. Considering the long thermal time constant of the mantle and the likely location of Pangea in the Permian, the situation may have been different prior to the present epoch [Anderson, 1982b]. The present continents have moved over colder mantle (mantle unaffected by continental insulation, sites of earlier subduction cooling, or oceanic lithosphere itself). In this regard it is of interest that eciogite xenoliths found in kimberlites apparently represent oceanic crust that was inserted at a depth of about $150 \mathrm{~km}$ under the African shield [Basu et al., 1986] and that deep continental peridotites resemble oceanic peridotites [Boyd and Mertzman, 1987]. The observations are difficult to reconcile with an ancient continental root, or tectosphere, extending to depths greater than $400 \mathrm{~km}$, or even $200 \mathrm{~km}$.

Lateral variations in composition probably exist below 200 $\mathrm{km}$, but these will be difficult to separate out from the firstorder effects of isobaric phase changes. Any inferences about chemically distinct continental roots extending below $200 \mathrm{~km}$ which ignore the larger effects of phase changes must be viewed with skepticism. In fact, there is a better correlation of deep upper mantle structure with young oceans than with shields [Nataf et la., 1986]. This probably indicates a deep source for oceanic basalts and a basalt-rich suboceanic mantle beneath oceanic lithosphere. However, the effects of isobaric phase changes swamp the more subtle effects of chemistry, and one cannot directly associate the low velocities under young oceanic regions, including the Red Sea-African $\mathbb{R}$ ift, or the high velocities under shields with chemically distinct "roots."

Acknowledgments. 1 appreciate extensive conversations with Brad IIager and Michael Gurnis and their critical review of the manuscript. Discussions with Fom Iordan have also been helpful. I thank Brad Hager, Rob Clayton, Fom Jordan, and Bob Engdahl for preprints. This research was supported by National Science Foundation grant FAR-8509350 and NASA gran! NSG-7610. Contribution 4444, Division of Geological and Planetary Sciences, California Institute of Technology, Pasadena, California.

\section{REFERENCES}

Akaogi, M., and S. Akimoto, Pyroxene-garnet solid solution equilibrium, Phys. Earth Planet. Inter., 15, 90-106, 1977.

Akaogi, M., N. L. Ross, P. McMillan, and A. Navrotsky, The $\mathrm{Mg}_{2} \mathrm{SiO}_{4}$. polymorphs (olivine, modified spinel and spinel)Thermodynamic properties from oxide melt solution calorimetry, phase relations, and models of lattice vibrations, Am. Mineral., 69 , $499-512,1984$

Akaogi, M., A. Navrotsky, T. Yagi, and S. Akimoto, Pyroxene-garnet transformation, paper presented at U.S.-Japan High-Pressure Conference, U.S.-Jpn. Seminar, Honolulu, Hawaii, Jan. 13-16, 1986.

Akimoto, S., The system $\mathrm{MgO}_{\mathrm{geO}}-\mathrm{SiO}_{2}$ at high pressure and temperature, Teclonophysics., 13, 161-187, 1972.

Anderson, D. L., Latest information from seismic observations, in The Earth's Mantle, pp. 355420 , Academic, Orlando, Fla., $1967 a$.

Anderson, D. L, Phase changes in the upper manule, Science, 157, 1165. $1173,1967 b$.

Anderson, D. L., Petrology of the mantle, Spec. Pap. Mineral. Soc. Am., 3, 85-93, 1970 .

Anderson, D. L., The upper mantle transition region: Eclogite?, Geophys. Res. Lett., 6, 433-436, 1979 a.

Anderson, D. L., Chemical stratification of the mantle, J. Geophys. Res., 84, 6297.6298, 19796.

Anderson, D. L., The deep structure of continents, I. Geophys Res., $84,7555-7560,1979 c$.

Anderson, D. L., Hotspots, basalts and the evolution of the mantle, Science, 213, 82-89, 1981 a.

Anderson, D. L., A global geochemical model fot the evolution of the mantle, in Evolution of the Earth, Geodyn. Ser., vol. 5, pp. 6-18, 19816 .

Anderson, D. L., The chemical composition and evolution of the mantle, High-Pressure Research in Geophysics, edited by S. Akimoto and M. H. Manghnani, Adv. Earth Planet. Soi., 12, 301-318, $1982 a$.

Anderson, D. L., Hotspots, polar wander, mesozoic convection, and the geoid, Nature, 97, 391-393, $1982 b$.

Anderson, D. L., Chemical composition of the mantle, Proc. Lunar Planet. Sci. Conf. 14th, part 1, J. Geophys. Res., 88, suppl., B41-B52, 1982 c.

Anderson, D. L., A seismic equation of state, II, Shear properties and thermodynamics of the lower mantle, Phys. Earth Planet. Inter., 45 , 307-323, $1987 a$.

Anderson, D. L., The depths of mantle resevoirs, in Magmatic Processes: Physiochemical Principles, Spec. Publ. 1, edited by B. O. Mysen, pp. 3-12, Geochemical Society, Dayton, Ohio, $1987 b$.

Anderson, D. L., and I. D. Bass, Mineralogy and composition of the upper mantle, Geophys. Res. Lett., 11, 637-640, 1984.

Anderson, D. L., and J. Bass, Transition region of the Earth's upper mantle, Nature, 320, 321-328, 1986.

Anderson, D. L., and R. L. Kovach, Attenuation in the mantle and ridigity of the core from muliple reflected core phises, Proc. Natl. Acad. Sci. U.S.A., 51, 168-172, 1964.

Anderson, D. L., and C. Sammis, The low-velocity zone, Geofis. Int., $9,319,1969$.

Anderson, D. L., and C. Sammis, Partial melting in the upper mantle, Phys. Earth Planet. Inter., 3, 41-50, 1970.

Anderson, D. L., and II. Spetzler, Partial melting and low-velocity zone, Phys. Earth Planet. Inter. 4, 62-64, 1970.

Anderson, O. L., E. Schreiber, R. Liebermann, and N. Soga, Some elastic constant data on minerals relevant to geophysics, Rev. Geophys., 6, 491-524, 1968.

Ando, M., SeS polarization anisotropy around the Pacific Ocean, $J$. Phys. Earth, 32, 179-196, 1984.

Basu, A., J. Ongley, and I. D. MacGregor, Eclogites, pyroxene geotherm, and layered mantle convection, Science, 233, 1303-1305, 1986.

Bock, G., The effect of the descending lithosphere beneath the Tonga island arc, Phys. Earth Planet. Inter., 25, 360-371, 1981

Boyd, F. R., High- and low-temperature garnet peridotite xenoliths and their possible relation to the lithosphere-asthenosphere boundary beneath southern Africa, in Manle Xenoliths, edited by P. H. Nixon, John Wiley, New York, in press, 1987.

Boyd, F. R., and S. Mertzman, Composition and structure of the Kaapvaal lithosphere southern Africa, in Magmatic Processes: Physiochemical Pinciples, Spec. Publ. 1, edited by B. O. Mysen, pp. 13-24, Geochemical Society, Dayton, Ohio, 1987.

Brune, J., and J. Dorman, Seismic waves and Earth structure in the Canadian Shield, Bull. Seismol. Soc. Am., 53, 167-210, 1963.

Butler, $\mathbb{R}$. and D. L. Anderson, Equation of state fits to the lower mantle and outer core, Phys. Earth Planel. Inter., 17, 147-162, 1978.

Creager, K. C., and T. H. Jordan, Slab penetration into the lower mantle, J. Geophys. Res., 89, 3031-3049, 1984.

Creager, $K$., and $T$. Jordan, Slab penetration into the lower mantle beneath the Mariana and other island arcs of the northwest Pacific, J. Geophys. Res., 91, 3573-3580, 1986.

Davies, D., and D. P. Mckenzie, Seismic travel-time residuals and plates, Geophys. J. R. Astron. Soc., 18,51-63, 1969

Engdahl, E. R., and D. Gubbins, Simulianeous travel time inversion for earthquake location and subduction zone structure in the central Aleutian lslands, $J$. Creophys. Res., this issue.

Fitch, T. J., Compressional velocity in source regions of deep earthquakes, Earth Planet. Sci. Lett., 26, 156-166, 1975.

frohlich, C., and M. Barazangi, A regional study of mantle velocity variations beneath eastern Australia and the southwestern Pacific using short-period recordings of $P, S, P c P, S c P$ and $S c S$ waves produced by Tonga deep earthquakes, Phys. Earth Planet. Inter., $32,1-14,1980$.

Fujimura, A., Preferred orientation of silicate spimel inferred from experimentally deformed aggregates of trevorite, 3 . Phys. Earth, 32, $273-296,1984$

Giardini, D., and J. H. Woodhouse, Deep seismicity and modes of deformation in Tonga subduction zone, Nature, 307, 505-509, 1984.

Giardini, D., and J. H. Woodhouse, Horizontal shear flow in the mantle beneath the Tonga arc, Nature, 319, 551--555, 1986.

Grand, S., and $\mathbb{D}$. Helmberger, Upper mantle shear structure of North America, Geophys, J. R. Astron. Soc., 76, 399-438, 1984. 
Griggs, D. T., The sinking lithosphere and the focal mechanism of deep earthquakes, in The Nature of the Solid Earth, edited by $\mathbb{E}$. C Robertson, pp. 361-384, McGraw-Mill, New York, 1972.

Hager, B. H., Subducted slabs and the geoid, J. Geophys. Res., 89, $6003-6015,1984$.

Hager, B. H., and R. Clayton, Constraints on the structure of mantle convection using seismic observations, flow models, and the geoid, in Mantle Convection, edited by W. R. Peltier, Gordon and Breach, New York, in press, 1987.

Hager, B., and R. O'Connell, Mantle flow driven by lithospheric thickening and subducted slabs, Eos Trans. $A G U, 59,1194,1978$.

Hager, B., R. O'Connell, and A. Faefsky, Subduction, back-arc spreading, and global mantle flow, Tectonophysics, 99, 165-189, 1983.

Hamaya, N., and S. Akimoto, Experimental investigation on the mechanism of the olivine-spinel transformation, in High-Pressure Research in Geophysics, edited by S. Akimoto and M. Manghnani, D. Reidel, Hingham, Mass., 1982.

Hirahara, K., A large-scale three-dimensional seismic structure under the Japan islands and the Sea of Japan, J. Phys. Earth, 25, 393-417, 1977.

Hirahara, K., and Y. Ishikawa, Travel time inversion for threedimensional $P$-wave velocity anisotropy, J. Phys. Earth, 32, 197 $218,1984$.

Huppert, L., and C. Frohlich, The $P$ velocity within the Tonga Beniofi zone, J. Geophys. Res., 86, 3771-3782, 1981.

Irifune, $\mathbb{T}$., and $\mathrm{A}$. Ringwood, Phase transformations in primitive MORB and pyrolite compositions to $25 \mathrm{GPa}$ and some geophysical implications, paper presented at U.S.-Japan High-Pressure Conference, U.S.-Jpn. Seminar, Honolulu, Hawaii, Jan. 13-16, 1986.

Irifune, T., T. Sekine, A. Ringwood, and W. Hibberson, The eclogitegarnet transformation at high pressure and some geophysical implications, Earth Planet. Sci. Lett., 77, 245-256, 1986.

Ito, E., and A. Navrotsky, $\mathrm{MgSiO}_{3}$ ilmenite: Calorimetry, phase equilibria and decomposition at atmospheric pressure, Am. Mineral., 70 , $1020-1026,1985$.

Ito, $\mathbb{E}$., and $\mathbb{E}$. Takahashi, Ultra high-pressure phase transformations and the constitution of the deep mantle, paper presented at U.S. Japan High-Pressure Conference, U.S.-Jpn. Seminar, Honolulu, Hawai, Jan. 13-16, 1986.

Ito, E., and H. Yamada, Stability relations of silicate spinels, ilmenite and perovskites, in High-Pressure Research in Geophysics, edited by S. Akimoto and M. Manghnani, pp. 405-420, D. Reidel, Hingham, Mass., 1982.

Jeanloz, $\mathbb{R}$., and $E$. Knittle, Reduction of mantle and core properties to a standard state by adiabatic decompression, in Chemistry and Physics of the Terrestrial Planets, edited S. K. Saxena, pp. 275-309, Springer-Verlag, New York, 1986.

Jordan, T. H., The continental tectosphere, Rev. Geophys., 13, 1-20 1975.

Jordan, T. H., Lithospheric slab penetration into the lower mantle beneath the Sea of Okhotsk, J. Geophys., 43, 473-496, 1977.

Jordan, T. H., Composition and development of the continental tectosphere, Nature, 274, 544-548, 1978.

Jordan, T. H., Mineralogies, densities and seismic velocities of garnet lherzolites and their geophysical implications, in The Mantle Sample: Inclusions in Kimberlites and Other Volcanics, edited by $\mathrm{H}$. O. A. Meyer and F. R. Boyd, pp. 1-14, AGU, Washington, D. C., 1979.

Kanzaki, M., Ultrahigh-pressure phase relations in the system $\mathrm{MgSiO}_{3}-\mathrm{Mg}_{3} \mathrm{Al}_{2} \mathrm{Si}_{3} \mathrm{O}_{12}$, Phys. Earth Planet. Inter., in press, 1987.

Kato, $T$, and $\mathbf{M}$. Kumazawa, Garnet phase of $\mathrm{MgSiO}_{3}$ filling the pyroxene-ilmenite gap at very high temperature, Nature, 316,803 $805,1985$.

Kato, T. and M. Kumazawa, Melting and phase relations in the $\mathrm{Mg}_{2} \mathrm{SiO}_{4}-\mathrm{MgSiO}_{3}$ system at $20 \mathrm{GPa}$ under hydrous conditions, $J$. Geophys. Res., 9I, 9351-9355, 1986.

Kaula, W. M., Material properties for mantle convection consistent with observed surface fields, J. Geophys. Res., 85, 7031-7044, 1980.

Kaula, W. M., Minimal upper mantle temperature variations consistent with observed heat flow and plate velocities, J. Geophys. Res., $88,10,323-10,332,1983$.

Kuskov, O. and R. Galimzyanov, Thermodynamics of stable mineral assemblages of the mantle transition zone, in Chemistry and Physics of the Terrestrial Planets, edited by S. K. Saxena, pp. 310-362, Springer-Verlag, New York, 1986.

Liu, L., Silicate perovskite from phase transformations of pyrote- garnet at high pressure and temperature, Geophys. Res. Lett., I, $277-280,1974$

Mckenzie, D. and B. Julian, Pugct Sound, Washington, earthquake and the mantle structure beneath the northwestern United States, Geol. Soc. Am. Bull., 82, 3519-3524, 1971

Nakanishi, I., and D. L. Anderson, Measurements of mantle wave velocities and inversion for lateral heterogeneity and anisotropy, II, Analysis by the single-station method, Geophys. J. R. Astron. Soc., $78,573-617,1984 a$

Nakanishi, I., and D. L. Anderson, Aspherical heterogeneity of the mantle from phase velocities of mantle waves, Nature, 307, 117-121, $1984 b$.

Nataf, H.-C., I. Nakanishi, and D. L. Anderson, Anisotropy and shear velocity heterogeneities in the upper mantle, Geophys. Res. Lett., 11, $109-112,1984$.

Nataf, H.-C., I. Nakanishi, and D. L. Anderson, Measurements of mantle wave velocities and inversion for lateral heterogeneities and anisotropy, 3, Inversion, J. Geophys. Res., 91, 7261-7307, 1986.

Navrotsky, A., F. S. Pintchovski, and S. I. Akimoto, Calorimetric study of the stability of high pressure phases in the systems $\mathrm{CoO}-\mathrm{SiO}_{2}$ and "FeO"- $\mathrm{SiO}_{2}$, and calculation of phase diagrams in MO-SiO, systems, Phys. Earth Planet. Inter., 19, 275-292, 1979.

Ohtani, E., Melting temperature distribution and fractionation in the lower mantle, Phys. Earth Planet. Inter., 33, 12-25, 1983.

Ohtani, E., The primoridial terrestrial magma ocean and its implications for stratification of the mantle, Phys. Earth Planet. Inter. $38,70-80,1985$

Ohtani, E., T. Kato, and H. Sawamoto, Melting of a model chondritic mantle to $20 \mathrm{GPa}$, Nature, 322, 352-354, 1986.

Ohtani, F., C. T. Herzberg, and T. Kato, Majorite stability, Earth Planet. Sci. Lett, in press, 1987.

Richards, M., Dynamical models for the Earth's geoid, Ph.D. thesis, Calif. Inst. of Technol., Pasadena, Calif., 1986.

Richards, M., and B. H. Hager, Geoid anomalies in a dynamic Earth, J. Geophys. Res., 89, $59876002,1984$.

Ringwood, A. E., Composition and Petrology of the Earth's Mantle, 618 pp., McGiraw-Hill, New York, 1975.

Ringwood, A. E., Phase transformations and differentiation in subducting lithosphere, J. Geol., 90,611 -643, 1982

Ringwood, A., and A. Major, The system $\mathrm{Mg}_{2} \mathrm{SiO}_{4}-\mathrm{Fe}_{2} \mathrm{SiO}_{4}$ at high pressures and temperatures, Phys. Earth Planet. Inter., 3, 89-108, 1970.

Ringwood, A. E., and A. Major, Synthesis of majorite and other high pressure garnets and perovskites, Larlh Planet. Sci. Lett., 12, 411 . $418,1971$.

Sawamoto, H., Phase equilibrium of $\mathrm{MgSiO}_{3}$ under high pressure and high temperature, paper presented at U.S.-Japan High-Pressure Conference, U.S.-Jpn. Seminar, Honolulu, Hawaii, Jan. $1316,1986$.

Sipkin, S. A., and T. H. Jordan, Lateral heterogeneity of the upper mantle determined from the travel times of ScS, J. Geophys. Res., $80,1474-1484,1975$.

Sipkin, S., and T. H. Jordan, Lateral heterogeneity of the upper manlle determined from the travel times of multiple $S c S, J$. Geophys. Res., 81, 6307-6320, 1976.

Tanimoto, T., and D. L. Anderson, Lateral heterogeneity and azimuthal anisotropy of the upper mantle: Love and Rayleigh waves 100-250s, J. Geophys. Res., 90, 1842-1858, 1985.

Toksör, M., M. Chinnery, and D. L. Anderson, Inhomogeneities in the Earth's mantle, Geophys. J. R. Astron. Soc., 13, 31-59, 1967.

Toksö $\angle$, N., J. W. Minear, and B. R. Julian, Temperature field and gephysical effects of a downgoing slab, J. Geophys. Res., 76, 1113 $1138,1971$.

Turcolte, D., and D. C. McAdoo, Geoid anomalies and the thickness of the lithosphere, $J$. Geophys. Res., 84, 2381 - 2387, 1979.

Weidner, D. J., Elasticity of $\mathrm{MgSiO}_{2}$ in the ilmenite phase, Phys. Earth Planet. Inter., 40, 65-70, 1985.

Woodhouse, J. H., and A. M. Dziewonski, Mapping the upper mantle, J. Geophys. Res., 89, 5953-5986, 1984.

Yamada, $\boldsymbol{H}$. and $\mathbb{E}$. Takahashi, Subsolidus phase relations between coexisting garnet and two pyroxenes at 50 to $100 \mathrm{~kb}$ in the system CaO-MgO-Al $\mathrm{O}_{3}-\mathrm{SiO}$, in Kimberlites, vol. Il, The Mantle and Crust Relationships, edited by J. Kornprobst, pp. 247. 255, Elsevier, Amsterdam, 1984.

D. L. Anderson, Seismological Laboratory, California Institute of Technology, Pasadena, CA 91125

(Received March 17, 1987;

revised July 21,1987

accepted August 6, 1987.) 